\title{
O sentido do ato cooperativo e o princípio de intercooperação na Lei uruguaia 18.409/2008
}

\author{
Guilherme Krueger \\ Programa de Pós-Graduação em Filosofia, Universidade Federal do Rio de Janeiro, \\ Comissão Especial de Direito Cooperativo, \\ Ordem dos Advogados do Brasil-Seccional do Rio de Janeiro
}

Recibido: $\quad$ 16.06.10

Aceptado: 28.06 .10

Em 14/11/2008, foi publicada a Lei uruguaia 18.407, que estabeleceu naquele país um regime geral para o sistema cooperativo, cuja base legal anterior era carente de uma unidade conceitual ${ }^{1}$. Nela, há uma interessantes referências à intercooperação. No II Seminário da Frente Parlamentar do Cooperativismo, ocorrido em Brasília em 16/09/2009, Danilo Gutiérrez, em comentários à novel Lei, descreveu um acontecimento2: o ato cooperativo cruzado - uma derivação face à tradição de ato cooperativo bilateral, pela qual se abandona a necessidade do vínculo societário como condição para o seu reconhecimento como tal ${ }^{3}$. O presente artigo se pretende como um contra-argumento a essa leitura do ato cooperativo.

Inicialmente, apenas para explicitar a referência, adotar-se-á a definição de intercooperação tal como expressa pela Aliança Cooperativa Internacional em seu Congresso Centenário (Manchester, 1995) e re-

1 Cf. Lavega, Sergio Reyes; Gutiérrez, Danilo. «Situación de la legislación cooperativa uruguaya». In: Cracogna, Dante (coord.). Régimen Legal de las cooperativas en los países del Mercosur. 2. ${ }^{a}$ ed., Buenos Aires: Intercoop, 2005, pp. 141-197.

2 Adoto aqui a expressão acontecimento para o imediato de fazer-se visível e nominável (o ser mora na linguagem e o homem habita essa morada) e o ser humano é tomado por esse acontecimento que dele se apropria. Acontecimento é o transcendente que se apodera do homem, que o toca. Aqui, a fenomenologia não mais se apresenta como visão dos objetos, tal como proposto por E. Husserl e M. Scheller, mas como interrogação pelo texto do ser, que se dissimula (retrai) no aparecimento do dado (um acontecimento que vela o acontecer), tal como propôs M. Heidegger.

3 «No ato cooperativo, não é o indivíduo o sujeito principal, mas a organização da qual toma parte; o indivíduo, por conseqüência, é sujeito do ato enquanto pertence à organização.» Puente, Antônio Salinas. Derecho cooperativo. Cidade do México: ECLAL, 1954, p. 132. 
cepcionada pela Recomendação 193 da Organização Internacional do Trabalho, votada em sua 90. ${ }^{a}$ Conferência, realizada em 20.06.2002:

As cooperativas servem de forma mais eficaz os seus membros e dão mais força ao movimento cooperativo, trabalhando em conjunto, através de estruturas locais, regionais, nacionais e internacionais. ${ }^{4}$

Essa referência é pertinente, na medida em que os princípios declarados pela Aliança, são expressamente evocados no art. $7 .^{\circ}$ da mesma Lei uruguaia 5 .

Também, à guisa de explicitar referência, ato cooperativo é um conceito positivado pela legislação aplicável às sociedades cooperativas em diversos países da América Latina. O ato cooperativo originalmente deu conta da dupla qualidade do sócio da cooperativa, como expressão da singular relação entre ambos, que se estabelece não somente na dimensão societária, isto é, num exercício próprio do direito de propriedade, mas numa dimensão operacional: o cooperado necessariamente integra sua atividade econômica à atividade econômica de sua cooperativa, de modo que o ganho marginal resultante da operação tende a se dar diretamente no patrimônio do sócio (distribuição de resultados conforme as operações) ou no patrimônio comunitário (não divisível). Neste sentido, lecionou o saudoso prof. Waldírio Bulgarelli:

«Nessa estrutura organizacional normativa das cooperativas (....), perfeitamente compreensível sobretudo na comparação com outros tipos societários existentes no nosso ordenamento, deve-se pôr em realce um elemento da maior importância para a compreensão da especificidade das sociedades cooperativas, e que quando não bem compreendido resulta num complicador capaz de toldar a visão da organização e funcionamento das cooperativas. Refiro-me, neste passo, ao aspecto operacional que inflete sobre o organizacional decorrente, que é da finalidade das cooperativas. Trata-se do fato de

4 Organização das Cooperativas Brasileiras. Informativo Especial para o I Encontro dos Segmentos do Cooperativismo Brasileiro. OCB: Brasília, 1995, p. 30.

5 «As cooperativas devem observar os seguintes princípios:

1. «livre adesão e demissão voluntária dos sócios;

2. "controle e gestão democrática pelos sócios;

4. «participação econômica dos sócios;

5. "autonomia e independência;

6. «educação, capacitação e informação cooperativa;

7. «cooperação entre cooperativas;

8. «compromisso com a comunidade». 
que elas, as cooperativas, são constituídas para prestar serviços aos seus próprios associados (....).

Trata-se de um verdadeiro princípio, denominado pela doutrina cooperativista como da dupla qualidade, que preside o sistema operacional, em que o associado é sócio e também usuário (sócio-cliente para os franceses). Decorre assim que da mutualidade (serviços comuns) e da cooperação (colaboração econômica) a cooperativa se apresenta como uma empresa auxiliar, cujo fim é a prestação de serviços aos seus associados, sendo o seu objeto o ramo de atividade escolhida (crédito, seguro, venda em comum da produção, fornecimento etc.).

Em termos jurídicos, verifica-se, pois, a existência de relações entre os associados e a cooperativa de duas naturezas: societárias e negociais. A vantagem do associado e que decorre do seu status de sócio é a de utilizar os serviços da cooperativa, obentdo um proveito ou uma redução de custos.»

\section{(...)}

«É tão importante este aspecto essencial da formação das cooperativas, que não só a doutrina dá-lhe sentido e ênfase, com as leis cooperativistas o regulam. Assim é que a Lei 5.764/71 não se limitou a dispor sobre a organização societária propriamente dita (constituição, administração, liquidação etc.), como ocorre nas demais sociedades, tendo ido além, para reger o que chamou de sistema operacional das cooperativas (....) sob a égide do qual regulou o ato cooperativo, a distribuição das despesas, as operações da cooperativa, o prejuízo e o sistema trabalhista.

Deu-se relevo assim às relações negociais entre cooperados e cooperativas, disciplinando o tipo de serviço a ser prestado, que é conexo ao objetivo da atividade (...) e em função deles a natureza do ato, configurado por isso como ato cooperativo. ${ }^{6}$

Como se depreende da lição de Bulgarelli, no cerne das práticas e operações das cooperativas, estão os chamados atos cooperativos. Os atos cooperativos, em sua conceituação original, têm aspectos essenciais e indeléveis que lhes são comuns:

a) intervenção de sócio e cooperativa;

b) objeto do ato idêntico ao objeto da cooperativa;

c) espírito de serviço. ${ }^{7}$

6 Direito Empresarial Moderno. Rio de Janeiro: Forense, 1992, pp. 337-338.

7 Cracogna, Dante Oswaldo. «El Acto Cooperativo», in: Primer Congreso Continental de Derecho Cooperativo. Merida: Universidad de Los Andes, 1969, pp. 205-211. 
Mas desde cedo houve pretensões de se dizer mais com a expressão ato cooperativo do que a sua noção ${ }^{8}$ original. As mais recorrentes ao longo dos anos designaram como atos cooperativos:

1. todos os atos os negócios jurídicos praticados entre a cooperativa e seus sócios, inclusive a constituição da própria sociedade, da qual todos os demais atos cooperativos derivam, e não somente os atos circunscritos na operacionalidade, isto é, na integração das respectivas atividades econômicas, o que é manifesto na condição da identidade de objetos.

2. todos os atos negociais praticados pela cooperativa com a finalidade de executar a operação na qual estão integradas as atividades econômicas da sociedade e de seus sócios. Neste caso, também podem ser atos cooperativos os praticados pela sociedade com terceiros. ${ }^{9}$

8 Adoto a expressão noção em contraste com o conceito e definição. As noções são vivências, conquanto conceitos e definições designam elaborações intelectuais. A noção é a flexão imaginária da consciência de alguma coisa, conquanto o conceito e a definição são reflexões racionais dessa vivência.

9 Cf. Krueger, Guilherme (coord.). Ato Cooperativo e seu Adequado Tratamento Tributário. Belo Horizonte: Mandamentos, 2004, p. 34. A Carta Jurídica de San Juan, expedida em 1976 por oportunidade do II Congresso Continental de Direito Cooperativo promovido pela Organização das Cooperativas das Américas aborda, em seu item 1.2.4, a dicotomia entre as teorias pura (bilateralidade cooperativa) e mista (unilateralidade cooperativa) como uma questão de alcance da noção do ato cooperativo. No Brasil, recentemente essa questão tem assumido uma pertinência relevante em vista das suas implicações para um adequado tratamento tributário ao ato cooperativo, tal como programa o art. 146, III, «C» da Constituição Federal. Mas há uma corrupção do termo: fala-se da extensão ou alcance do ato cooperativo, em si. O ato cooperativo ter extensão ou alcance é uma afirmação tão verdadeira como a que círculo tem quina. Verdade aqui é tomada como referência lógica, em contraste com a validade como referência axiológica. Ora, aqui se comete então um erro de fundamento: ato cooperativo, tal como legislado, é manifestação de vontade. Extensão não é categoria própria para a vontade, e sim potência. Há na busca de uma extensão delimitada no ato cooperativo uma confusão entre atos cooperativos e fatos - as operações, que decorrem do ato cooperativo por nexo de causalidade. Afinal, a tributação não incide sobre a vontade manifesta. Não é logicamente possível adequar um tratamento tributário ao ato cooperativo, a partir de sua leitura mais tradicional e (porque não dizer?) mais rigorosa. As hipóteses tributárias falam de fatos e o sentido desses fatos é o que faz atrair a atenção para o ato cooperativo, eis que sua manifestação ideal condiciona a doação racional de sentidos a esses fatos sobre as quais se examina a incidência de um tributo. Essa confusão evidencia a necessidade de exame do contexto em que se emprega a expressão ato cooperativo, admitindo-se então uma polissemia para a superação do problema. A esse respeito, conferir Krueger, Guilherme. "Por que integrar as Universidades ao debate contemporâneo sobre o Direito Cooperativo no Brasil?», in: Boletín de la Associación Internacional de Derecho Cooperativo, n. ${ }^{\circ}$ 42. Bilbao: Universidad de Deusto, 2008, pp. 175-186. 
Em 1994, o Paraguai sancionou a Lei 438, que definiu o ato cooperativo a partir da noção mais difusa:

Art. 8. $^{\circ}$

O ato cooperativo é a atividade solidária, de ajuda mútua e sem fins de lucro, de pessoas que se associam para satisfazer necessidades comuns ou fomentar o desenvolvimento. O primeiro ato cooperativo é a assembléia geral constitutiva e a aprovação do estatuto. São também atos cooperativos os realizados por: a) as cooperativas com seus sócios; b) as cooperativas entre si; c) as cooperativas com terceiros em cumprimento de seu objeto social. Neste caso, reputase ato misto e somente será ato cooperativo em relação à cooperativa (....).

Essa definição do ato cooperativo contrasta com a sua positivação mais antiga, de 1971, na Lei brasileira n. ${ }^{\circ} 5.764$, bem mais restrita (pura):

\section{Art. 79}

Denominam-se atos cooperativos aqueles praticados entre as cooperativas e seus associados, entre estes e aqueles e pelas cooperativas entre si quando estão associadas para a consecução de objetos sociais.

$\S$ único

O ato cooperativo não implica operação de mercado, nem contrato de compra e venda de produto ou mercadoria.

De volta à intercooperação, mesmo adotando-se a definição mais restrita de ato cooperativo, nele pode ela se reconhecer: as cooperativas praticam atos cooperativos entre si. Não necessariamente numa relação operacional organizada verticalmente e formalizada em negócios firmados entre cooperativas de grau inferior e de grau superior (singulares com centrais e federações e estas com confederações). No caso do Brasil, onde, como visto, o vínculo societário preexistente entre as partes é requisito para a qualificação de um ato por elas praticado como cooperativo, o Conselho Nacional de Cooperativismo, nas Resoluções n. ${ }^{\circ} 21$ e 28, respectivamente de 20/10/1981 e de 13/02/86, reconheceu a validade da associação de cooperativa em outra de mesmo grau, independentemente de seus objetos. Há nessas Resoluções nexo lógico necessário em admitir o CNC a prática de atos cooperativos entre elas, sem os quais o vínculo societário perderia sentido por impossi- 
bilidade de prestação de serviços, conforme a inteligência dos arts. $4 .^{\circ}$, I, 7.․ 8. ${ }^{\circ}$ e 35 , IV da Lei 5.764/7110.

De volta agora à novel Lei uruguaia, assim define o ato cooperativo:

\section{Art. 9. ${ }^{\circ}$}

São atos cooperativos os realizados entre cooperativas e seus sócios, por elas e os sócios de suas cooperativas sócias, ou pelas cooperativas entre si, quando estiverem associadas por qualquer forma ou vinculadas por filiação a outra de grau superior, em cumprimento de seu objeto social.

Os mesmos constituem negócios jurídicos específicos, cuja função econômica é a ajuda mútua, ficam submetidos ao direito cooperativo e para sua interpretação se entenderão integrados conforme as disposições estatutárias.

Terão por objeto a criação, modificação ou extinção das obrigações, negócios dispostos em sentido amplo ou em sentido estrito.

Em caso de inadimplemento, a parte à qual cabe o direito poderá optar entre a execução forçada ou a resolução, ou rescisão segundo o caso, cumulado da indenização por perdas e danos. Dever-se-á solicitar judicialmente e o juiz poderá estabelecer um prazo de purgação da mora.

No que as leis cooperativas forem omissas, se aplicarão ao ato cooperativo os princípios gerais em matéria de negócio jurídico em geral e dos contratos em particular, no que for compatível e enquanto lhe corresponder ou lhe ser pertinente.

Os vínculos das cooperativas com seus trabalhadores dependentes se regem pela legislação trabalhista.

10 Art. $4 .^{\circ}$ As cooperativas são sociedades de pessoas, com forma e natureza jurídica próprias, de natureza civil, não sujeitas a falência, constituídas para prestar serviços aos associados, distinguindo-se das demais sociedades pelas seguintes características:

I. adesão voluntária, com número ilimitado de sócios, salvo impossibilidade técnica de prestação de serviços;

...

Art. $7 .^{\circ}$. As cooperativas singulares se caracterizam pela prestação direta de serviços aos associados.

Art. 8. $^{\circ}$. As cooperativas centrais e federaçõs de cooperativas objetivam organizar em comum e em maior escala os serviços econômicos e assistenciais de interesse das filiadas, integrando e orientando suas atividades, bem como facilitando a utilização recíproca de serviços.

Art. 35. A exclusão do associado será feita:

IV. Por deixar de atender aos requisitos estatutários de ingresso ou permanência na cooperativa. 
No que se refere à definição de ato cooperativo, pode-se afirmar que a Lei uruguaia está próxima ao pólo de pureza da que está positivada no Brasil, se considerada a Lei paraguaia como um outro extremo do arco de possibilidades semânticas ${ }^{11}$ no atual estado das artes. Variação significativa é a sua flexibilidade, quanto à estrita correspondência entre o vínculo operacional decorrente do ato cooperativo e o vínculo societário como seu pressuposto formal: há ato cooperativo entre o sócio da cooperativa singular e a Central a que aquela é sócia - e não ele, o que dá sentido ao disposto no art. 80, item D. Assim dispõe esse dispositivo:

\section{Art. 80}

Por razões de interesse social ou quando for necessário para o melhor desenvolvimento de sua atividade econômica, sempre que não comprometa sua autonomia, as cooperativas poderão prestar serviços próprios de seu objeto social a não sócios, aos quais não poderão outorgar condições mais favoráveis do que as concedidas aos sócios. Os excedentes líquidos que derivem a estas operações serão destinados conforme previsto no art. $70^{12}$ da presente Lei.

11 Semântica é o sentido e a aplicação das palavras em um contexto.

12 Art. 70. "A Assembléia Geral Ordinária determinará o destino dos excedentes líquidos do exercício, de acordo com a seguinte ordem:

1. pagar os juros previstos nos instrumentos de capitalização;

2. recompor as rubricas patrimoniais, quando tenham diminuído pela absorção de perdas de exercícios anteriores e compensar as perdas ainda pendentes de absorção.

O remanescente se destinará de acordo com a seguinte ordem:

1. pelo menos $15 \%$ para a constituição de uma reserva legal, até que esta se igual ao capital, reduzindo-se então para 10\% a partir daí e cessando a destinação quando corresponder ao triplo do capital.

2. Pelo menos $5 \%$ para uma Reserva para Educação e Capacitação Cooperativa.

3. Pelo menos $10 \%$ para a constituição de uma reserva na eventualidade de operações com não sócios.

E o saldo será destinado à distribuição entre os sócios na forma de retorno ou como pagamento de juros às quotas-partes integralizadas limitados aos juros praticados no mercado, conforme determinação da Assembléia.

O montante a ser distribuído entre os sócios na forma de retorno não poderá ser inferior a 50\% do remanescente e terá as seguintes condições:

A) Nas cooperativas de primeiro grau, em proporção às operações realizadas com a cooperativa ou ao trabalho realizado nela;

B) Nas cooperativas de segundo ou ulterior grau, em proporção ao capital social aportado ou aos serviços utilizados, conforme estabelecido em estatuto.» 
Não se considerarão operações realizadas com não sócios, as que se efetuem com os seguintes fins:

A) «para servir a sócios de outra cooperativa;

B) «para alienar bens do ativo fixo os quais a cooperativa tem ociosos ou depreciados

C) «para servir ao público, por motivo de utilidade geral, a requerimento do poder público;

D) «no caso das cooperativas de segundo ou ulterior grau, também aquelas operações que se realizem com os sócios de suas entidades sócias;

E) «As operações que se realizem entre cooperativas.

Antes de avançar com relação à intercooperação, é interessante explicitar o fundamento para o vínculo entre os arts. 70 e 80 de modo que bem se distinga esse não sócio a que se referem estes dispositivos, de modo a esclarecer o sentido do rol de exclusões que aparece no último artigo citado. Pertinente aqui retomar a distinção entre finalidade e objeto. Na lição de WALMOR FRANKE:

"O fim da cooperativa é a prestação de serviços ao associado, para a melhoria do seu status econômico. A melhoria econômica do associado resulta do aumento do seus ingressos ou da redução de suas despesas, mediante a obtenção, através da cooperativa, de créditos ou meios de produção, de ocasiões de elaboração e venda de produtos, e a consecução de poupanças.»

"Objeto do empreendimento cooperativo é o ramo de sua atividade empresarial; é o meio pelo qual, no caso singular, a cooperativa procura alcançar o seu fim, ou seja, a melhoria da situação econômica do cooperado» ${ }^{13}$.

13 Direito das sociedades cooperativas. São Paulo: Saraiva; Ed. da Universidade de São Paulo, 1973, p. 15. Na doutrina de Waldirio Bulgarelli (As sociedades cooperativas e a sua disciplina jurídica. RJ: Renovar, 1998, p. 107), trata-se da delegação:

Verifica-se, assim, que as cooperativas atuam com seus associados, dentro de círculo, com atos caracterizados como internos e praticados em razão do contrato societário. (....)

Não há portanto propriamente mandato ou representação, no sentido estrito, mas aquilo que denominamos delegação cooperativa, que se caracteriza por uma representação especificamente operacional, tendo em vista os objetivos e as formulações do contrato societário. Se se admite no direito comercial o mandato sem representação, típico do contrato de comissão, em que o comissário opera em seu próprio nome, porém de acordo com as ordens e instruções do comitente, não passando afinal de um prestador de serviços, nada há de estranhável que no Direito Cooperativo, opere-se a delegação, pela qual a sociedade, recebendo pelo ISSN: 1134 - 993X, Núm. 44/2010, Bilbao, págs. 145-158 
Na doutrina de WALDIRIO BULGARELLI, trata-se de uma delegação o nexo entre o fim e o objeto da cooperativa:

Verifica-se, assim, que as cooperativas atuam com seus associados, dentro de círculo, com atos caracterizados como internos e praticados em razão do contrato societário. (....)

Não há portanto propriamente mandato ou representação, no sentido estrito, mas aquilo que denominamos delegação cooperativa, que se caracteriza por uma representação especificamente operacional, tendo em vista os objetivos e as formulações do contrato societário. Se se admite no direito comercial o mandato sem representação, típico do contrato de comissão, em que o comissário opera em seu próprio nome, porém de acordo com as ordens e instruções do comitente, não passando afinal de um prestador de serviços, nada há de estranhável que no Direito Cooperativo, opere-se a delegação, pela qual a sociedade, recebendo pelo contrato social, um mandato específico, opera em seu próprio nome, porém para o associado, prestando-lhe serviços naquele perfeitamente estabelecidos, que decorrem do objeto específico da Cooperativa. ${ }^{14}$

Porém, não necessariamente a cooperativa logra proveito aos seus sócios na plenitude de sua potencialidade apenas operando com a delegação (mandato sem representação). Quando a cooperativa operar sem a integração econômica de uma atividade do sócio, ou seja, sem a presença do ato cooperativo, a cooperativa de certo modo estará se desviando de sua finalidade, ainda que seja, num sentido oblíquo de sua razão econômica, assim possa proceder para melhor cumprir a sua finalidade. Este é o sentido do art. 80.

Se a cooperativa realiza uma operação sem praticar o ato cooperativo, é porque o sócio não figura na condição de usuário sem interesse oposto à da sociedade. Neste caso, o sócio resta apenas na condição de titular da cooperativa. Seria destinatário dos resultados líquidos da operação, como o proprietario de qualquer sociedade. A cooperativa então operaria sem ser por conta do sócio, mas por sua própria conta para lograr a obtenção desses resultados e, ao fim e ao cabo, distribuílas aos sócios. Se esses resultados marginais fossem distribuídos conforme a titularidade patrimonial da sociedade, estar-se-ia diante da distribuição do lucro; sendo o lucro a finalidade da operação realizada.

contrato social, um mandato específico, opera em seu próprio nome, porém para o associado, prestando-lhe serviços naquele perfeitamente estabelecidos, que decorrem do objeto específico da Cooperativa.

14 As sociedades cooperativas e a sua disciplina jurídica. RJ: Renovar, 1998, p 107. 
Mas, dada a solução da Lei uruguaia, ao admitir que a cooperativa opere sem praticar atos cooperativos, admite que a cooperativa derive, em seu ponto de partida operacional, de sua finalidade. Porém, esse desvio não se consuma no fim por uma inibição: este é o sentido de existência do item 3 do art. 70.

Esse sentido é necessário para se identificar os chamados negócios acessórios, exemplificados no item B do art. 80 da Lei uruguaia. São esses negócios indiretamente vinculados com o objeto da cooperativa ou com a finalidade da cooperativa, mas que em todo o caso existem em razão das operações realizadas pelos sócios com suas cooperativas. Neste passo, importante sempre identificar um nexo de dependência do negócio-acessório com o negócio-meio e com o negócio-fim. ${ }^{15}$

O item C claramente manifesta a contemplação do $7 .^{\circ}$ princípio de identidade universal da Aliança Cooperativa Internacional em seu Congresso Centenário (Manchester, 1995) e recepcionada pela Recomendação $193^{16}$. Então, na ponderação dos princípios ${ }^{17}$ expressos no art. 7. ${ }^{018}$, é evidente que há uma equiparação do item $C$ ao tratamento adequado às operações decorrentes do ato cooperativo, o que prestigia o princípio de participação econômica do sócio. Neste viés, é possível examinar também os itens $\mathrm{A}$ e $\mathrm{E}$.

Nem o item A nem o E precisam ser considerados atos cooperativos para adequar a Lei uruguaia aos seus propósitos, pois nessas hipóteses não há a manifestação da dupla condição de usuário e dono de uma cooperativa em relação à outra. Mesmo que o item $\mathrm{D}$, como visto, flexibilize a estrita observância formal dessa condição, dela não prescinde,

\section{Acessorium sequitur principale}

16 «Interesse pela comunidade. As cooperativas trabalham para o desenvolvimento sustentado de suas comunidades, através de políticas aprovadas pelos membros». (Organização das Cooperativas Brasileiras, ob. cit., p. 30).

17 «É que, diferentemente das regras de direito, os princípios jurídicos não se apresentam como imperativos categóricos, mandatos definitivos nem ordenações de vigência diretamente emanados do legislador, antes apenas enunciam para que o seu aplicador se decida neste ou naquele sentido. Noutras palavras, enquanto em relação às regras e sob determinada concepção de justiça, de resto integrada na consciência jurídica geral, o legislador desde logo e com exclusividade define os respectivos suposto e disposição, isto é, cada hipótese de incidência e a respectiva conseqüência jurídica, já no que se refere aos princípios jurídicos — daí o seu caráter não conclusivo, anota Hartesse mesmo legislador se abstém de fazer isso, ou pelo menos de fazê-lo sozinho e por inteiro, preferindo compartilhar a tarefa com aqueles que irão aplicar esses standarts normativos, porque sabe de antemão que é somente em face de situações concretas que elas logram atualizar-se e operar como verdadeiros mandatos de otimização.» (Mendes, Gilmar Ferreira et al. Curso de Direito Constitucional. SP: Saraiva/Instituto Brasiliense de Direito Público, 2007, p. 27).

18 Ver nota 4. 
pois impõe a necessidade da sucessão de vínculos societários, através da cooperativa de grau inferior.

É necessário compreender o sentido dessa imposição: o ato cooperativo, como manifestação de vontade em sua noção original, emerge como um ente que difere radicalmente dos atos de mercado. Sseu fundamento é a ausência de oposição de interesses de conteúdo econômico entre as partes que praticam o negócio. Essa identidade de interesses de conteúdo econômico entre a cooperativa e seu sócio individualmente considerado se manifesta como um proveito comum a todos os sócios - todos eles igualmente usuários da cooperativa.

Equívoco de premissa muito comum entre aqueles que proseiam sobre cooperativas é a afirmativa que os cooperados têm em comum a unidade empreendedora como elemento suficiente para a visualização do proveito. Este status por si só não é suficiente para singularizar uma cooperativa. Toda sociedade tem tal conotação. A identidade que singulariza a cooperativa é o proveito que os cooperados dela retiram ${ }^{19}$. Em outras palavras, as espécies de serviços que a cooperativa presta deve ter por alvo indistinto todos os associados, de forma efetiva ou potencial20.

De outra forma, dificilmente se poderia aferir objetivamente o abuso de forma cooperativista consubstanciado na vedação legal de distribuição de vantagens ou privilégios financeiros ou não em favor de quaisquer associados em detrimento dos demais, que não seja decorrente da própria integração de suas atividades econômicas..

O proveito comum não é um elemento subjetivo de Direito. Ele é um elemento objetivo que exsurge do cotejo dos serviços que a cooperativa presta aos seus associados e o seu objeto societário ${ }^{21}$, no sentido

19 Assim é que Salinas Puente conceitua o ato cooperativo como um ato coletivo, pois os sócios «querem produzier face a terceiros um único e igual efeito jurídico querido por todos: não se contrapõem como partes, mas que formam, unidos entre si, uma só parte» (ob. cit., p. 152).

20 «(...) o proveito comum dos associados que configura a grande meta da cooperativa: ela se destina fundamentalmente a proporcionar serviços a seus associados, mormente os de ordem econômica.» Machado, Plínio Antônio. Comentários à Lei do Cooperativismo. SP: Unidas, 1975, p. 26.

21 «Relativamente à indicação do objeto da sociedade ressaltamos que a norma alude à atividade dos associados, eis que a cooperativa — por si só — tem como objeto a prestação de serviços aos seus associados. Portanto, compondo a norma em face da disposição acima entendemos que a exigência de que os estatutos das sociedades cooperativas indiquem o objeto diz respeito à designação da modalidade de "bens e serviços" que os cooperados "se obrigam a contribuir" (art. 3..$^{\circ}$.» LIMA, Reginaldo Ferreira. Direito Cooperativo Tributário e Comentários à Lei das Sociedades Cooperativas. SP: Max Limonad, 1997, p. 99. 
de se identificar a unidade de seus destinatários —o conjunto de seus associados, cujas atividades econômicas se integram na cooperativa numa homogeneidade de interesses-.

Essa percepção é fundamental para a distinção do que é uma cooperativa mista do abuso de sua forma. Naturalmente a cooperativa poderá possuir mais de um objeto. Ou seja, os associados podem realizar mais de uma atividade econômica junto à cooperativa, desde que o destinatários dos diferentes serviços pertinentes a essas atividades (atos cooperativos) sejam os mesmos, e não opostos.

A cooperativa de produção agropecuária com seção de crédito é uma cooperativa mista. Porque o usuário dos diferentes serviços prestados pela cooperativa (o crédito e o beneficiamento e comercialização do produto rural) é sempre o mesmo: o produtor rural.

A cooperativa de médicos que associa pacientes constitui abuso de forma. Não há unidade neste caso no quadro social da cooperativa. A desunião que interessa à identificação do abuso está na diferença de interesses econômicos em jogo. No caso, os interesses de ordem econômica são potencialmente conflitivos: ao médico interessa obter a maior renda possível pelo serviço prestado; ao paciente interessa a menor despesa possível pelo mesmo serviço. Considerando que a cooperativa justamente atende aos interesses econômicos do seu associado, não há proveito econômico comum entre o médico e seu paciente. Enfim, é impossível reconhecer neste caso a prática de atos cooperativos: médicos e pacientes não cooperam em suas respectivas atividades econômicas ${ }^{22}$. Entre eles há uma relação de mercado, ainda que mitigado pelo interesse comum de preservar a saúde o melhor possível.

O mesmo diz-se quanto à impossibilidade de prática só de atos cooperativos numa operação que envolva a relação econômica entre pais e mestres. Ainda que todos possam ter um interesse comum pela melhor educação possível, este interesse não é de conteúdo essencialmente econômico. É claro que o professor deseja a melhor remuneração possível para o seu trabalho e os pais querem o menor custo possível para a melhor educação que lograrem oferecer aos seus rebentos. É

22 «O método de atividade na sociedade cooperativa consiste na prática de atos que diminuam o custo da produção, de jeito a haver vantagem para os sócios, que são os consumidores, ou que levem à obtenção de melhor preço para os produtores, pois os produtores são os sócios, ou a conclusões de empréstimos com menores interesses.» (Pontes de Miranda. Tratado de Direito Privado, tomo XLIX, 3. ${ }^{a}$ ed. Rio de Janeiro: Borsoi, 1972, p. 432.) E que atos são esses, a que Pontes de Miranda se referiu ? Todo cooperativista latino-americano tem na ponta da língua: são os atos cooperativos ! ISSN: 1134 - 993X, Núm. 44/2010, Bilbao, págs. 145-158 
curioso demonstrar que neste caso há a hipossuficiência trabalhista dos professores pela própria afirmação da singularidade de voto que caracteriza a cooperativa: é razoável supor que haverão mais pais do que mestres em qualquer cooperativa que propusesse a filiação de ambos. Neste modo, é crível supor que na assembléia haverá a tendência de preponderar os interesses econômicos dos pais em detrimento dos professores, de modo que a supremacia assemblear não é suficiente para a garantia da dignidade e decência do trabalho deles.

O que se pretende argumentar é que o ato cooperativo só pode ser reconhecido para uma parte específica do conjunto de possibilidades de intercooperação. É claro que pode haver intercooperação entre pais e mestres, na medida em que se organizem em cooperativas e elas contratem entre si. O mesmo é possível entre cooperativas de consumo e cooperativas agropecuárias. Há a intercooperação, mas não a prática de atos cooperativos, tal como conceituado na Lei brasileira ou uruguaia, condizente com a sua própria noção original, em que se buscou afirmar a sua alteridade, isto é, o que ele não é: um ato de mercado ${ }^{23}$. Pois o interesse econômico dos sócios de uma cooperativa, que é o mesmo dela, se opõe no mercado ao interesse econômico dos sócios da outra cooperativa, eis que há só identidade de interesses entre si.

Mas, o que é previsto no art. 80 da Lei uruguaia é a equiparação entre o tratamento adequado dado às operações decorrentes dos atos cooperativos e os decorrentes dos atos intercooperativos no mercado. Neste sentido, a novel Lei uruguaia foi feliz em estimular o cooperativismo e otimizar o mandato da intercooperação, sem que precisasse abandonar a tradição conceitual do ato cooperativo, cuja importância está na facilitação de compreensão e preservação da identidade operacional das cooperativas face ao que há por paradigma na operação de mercado. Neste ponto, a Lei uruguaia permanece fiel às originais idéias de Salinas Puente, que permanecem atuais e ainda ganham maior relevância numa circunstância crítica, como a que se vive globalmente:

As definições do ato de mercado não negam de todo a existência de dois fatores essenciais: a interposição na circulação de mercadorias e o lucro, que é o motivo dessa ação. Este propósito especulativo alcançou proporções extraordinárias e isso enseja um desequilíbrio coletivo. (....)

23 «não é só a realização de uma atividade econômica no interesse de um particular; mas principalmente a satisfação das necessidades comuns por meios coletivos.» Puente. ob. cit., p. 160. 
No contexto dessa voracidade, o Direito Cooperativo pretende constranger os membros da organização cooperativa que fixem um preço justo tanto quanto seja possível, num esforço contínuo para se obter um barateamento do custo de vida.

Desta maneira, se evitará também toda forma de exploração do homem pelo homem, dando a cada um o valor íntegro de seu trabalho. ${ }^{24}$

24 Ob. cit., p. 155. 